\title{
Higher Midazolam Clearance in Obese Adolescents Compared with Morbidly Obese Adults
}

\author{
Anne van Rongen ${ }^{1,2,10}$ ( Margreke J. E. Brill $^{1,2,11} \cdot$ Janelle D. Vaughns ${ }^{3,4}$. \\ Pyry A. J. Välitalo ${ }^{2}$ Eric P. A. van Dongen ${ }^{5}$ - Bert van Ramshorst ${ }^{6}$. \\ Jeffrey S. Barrett ${ }^{7} \cdot$ Johannes N. van den Anker, $^{4,89} \cdot$ Catherijne A. J. Knibbe $^{1,2}$
}

Published online: 7 August 2017

(C) The Author(s) 2017. This article is an open access publication

\begin{abstract}
Background The clearance of cytochrome P450 (CYP) 3A substrates is reported to be reduced with lower age, inflammation and obesity. As it is unknown what the overall influence is of these factors in the case of obese adolescents vs. morbidly obese adults, we studied covariates influencing the clearance of the CYP3A substrate midazolam in a combined analysis of data from obese adolescents and morbidly obese adults.

Methods Data from 19 obese adolescents [102.7 kg $(62-149.5 \mathrm{~kg})]$ and 20 morbidly obese adults [144 kg $(112-186 \mathrm{~kg})]$ receiving intravenous midazolam were analysed, using population pharmacokinetic modelling (NONMEM 7.2). In the covariate analysis, the influence of study group, age, total body weight (TBW), developmental weight $\left(\mathrm{WT}_{\text {for age and length }}\right)$ and excess body weight $\left(\mathrm{WT}_{\text {excess }}=\mathrm{TBW}-\mathrm{WT}_{\text {for age and length }}\right)$ was evaluated.
\end{abstract}

Electronic supplementary material The online version of this article (doi:10.1007/s40262-017-0579-4) contains supplementary material, which is available to authorized users.

Catherijne A. J. Knibbe

c.knibbe@antoniusziekenhuis.nl

1 Department of Clinical Pharmacy, St. Antonius Hospital, Koekoekslaan 1, 3435 CM Nieuwegein, The Netherlands

2 Division of Pharmacology, Leiden Academic Centre for Drug Research, Leiden University, Leiden, The Netherlands

3 Division of Anesthesiology and Pain Medicine, Children's National Health System, Washington, DC, USA

4 Division of Clinical Pharmacology, Children's National Health System, Washington, DC, USA

5 Department of Anesthesiology and Intensive Care, St. Antonius Hospital, Nieuwegein, The Netherlands
Results The population mean midazolam clearance was significantly higher in obese adolescents than in morbidly obese adults $[0.71(7 \%)$ vs. $0.44(11 \%) \mathrm{L} / \mathrm{min}$; $p<0.01]$. Moreover, clearance in obese adolescents increased with TBW $(p<0.01)$, which seemed mainly explained by $\mathrm{WT}_{\text {excess}}$, and for which a so-called 'excess weight' model scaling $\mathrm{WT}_{\text {for age and length }}$ to the power of 0.75 and a separate function for $\mathrm{WT}_{\text {excess }}$ was proposed.

Discussion We hypothesise that higher midazolam clearance in obese adolescents is explained by less obesity-induced suppression of CYP3A activity, while the increase with $\mathrm{WT}_{\text {excess }}$ is explained by increased liver blood flow. The approach characterising the influence of obesity in the paediatric population we propose here may be of value for use in future studies in obese adolescents.
6 Department of Surgery, St. Antonius Hospital, Nieuwegein, The Netherlands

7 Laboratory for Applied PK/PD, Children's Hospital of Philadelphia, Philadelphia, USA

8 Division of Pediatric Pharmacology and Pharmacometrics, University Children's Hospital, Basel, Switzerland

9 Intensive Care and Department of Pediatric Surgery, Erasmus MC-Sophia Children's Hospital, Rotterdam, The Netherlands

10 Present Address: Department of Clinical Pharmacy, Reinier de Graaf Hospital, Delft, The Netherlands

11 Present Address: Department of Pharmaceutical Biosciences, Uppsala University, Uppsala, Sweden 


\section{Key Points}

Midazolam clearance is higher in obese adolescents compared with morbidly obese adults, which shows that it is not justified to assume that clearance is lower in obese adolescents compared with obese adults.

In obese adolescents, midazolam clearance increased mainly with $\mathrm{WT}_{\text {excess }}\left(=\mathrm{TBW}-\mathrm{WT}_{\text {for age and length }}\right)$ for which a novel modelling approach was proposed with 0.75 allometric scaling on the basis of $\mathrm{WT}_{\text {for age and length }}$ and a separate function for $\mathrm{WT}_{\text {excess. }}$

With this so-called excess weight model, we propose a novel approach characterizing the influence of obesity in the paediatric population, providing guidance on data analysis for future paediatric obesity studies.

\section{Introduction}

Cytochrome P450 (CYP) 3A is an important enzyme system, responsible for the primary metabolism of $25 \%$ of all clinically used drugs [1]. This enzyme system is known to vary with age, inflammation and obesity [2-6]. Its activity is reported to be low at birth and reaches adult values in the first years of life [6,7], after which the size of the liver and/ or liver flow determines the increase in CYP3A clearance. Recently, a study on midazolam, a well-known probe for CYP3A [8, 9], showed that this system is also highly influenced by inflammation and sepsis in children [4]. In obesity, which may be seen as a chronic state of inflammation, reduced CYP3A protein expression or CYP3A activity has been reported in in-vitro and obese mice studies [10-13]. Moreover, in humans, reduced oral clearance of midazolam in obese subjects compared with non-obese subjects was reported for various CYP3A substrates [3], even though no difference in midazolam clearance in obese vs. non-obese individuals was found [14]. Yet, a 1.7-fold increase in midazolam clearance in patients 1 year after bariatric surgery was reported, indicating a reduced CYP3A hepatic activity in these morbidly obese individuals before their weight loss surgery [15-17].

An important question is how the CYP3A system is influenced by both age and obesity, particularly in view of the increasing prevalence of obesity in both adults and children [18]. Allometric scaling on the basis of body weight with an exponent of 0.75 is often used to describe the finding that clearance in children is generally lower than in adults [19-21]. In particular, there is agreement on this approach for adolescents. The US Food and Drug Administration already proposed in 2012 that allometric scaling based on adult data, without the use of a dedicated pharmacokinetic study, is a reasonable approach for scaling to adolescents [22]. More recently, there is further evidence to use allometric scaling in (non-obese) children above the age of 5 years [23]. However, given the increase in body weights of both adults and children observed presently as a result of the obesity epidemic [18], this approach that uses body weight as a proxy for size, may be questionable in obese individuals.

A combined (covariate) analysis of data from both obese adolescents and obese adults may give an appropriate answer to this question. As total body weight (TBW) in the obese individual consists of the sum of body weight related to development ( $\mathrm{WT}_{\text {for age and length }}$ ) and excess body weight related to obesity ( $\mathrm{WT}_{\text {excess }}$ ), in such an analysis, potentially a different influence of these types of weight may be expected on a specific pharmacokinetic parameter [24]. While for clearance body weight related to size (WT for age and length $_{\text {, }} 0.75$ allometric scaling may be applied [23], $\mathrm{WT}_{\text {excess }}$ may or may not have an impact. For instance for some drugs, adult clearance is known to vary with obesity while this is not the case for others [3]. Moreover, even when obese adolescents have the same body weight as obese adults, the (patho)physiologic changes associated with obesity, for instance inflammation $[25,26]$, exist for a shorter time, thereby potentially altering their influence.

In this article, we study the clearance of the CYP3A substrate midazolam in obese adolescents and morbidly obese adults in a combined analysis. Moreover, we explore a model that can be used to consider obesity in the paediatric population, given the obesity epidemic we are currently facing.

\section{Methods}

\subsection{Patients}

Model building was based on data from 19 adolescents [27] and 20 adults [14]. The study in obese adolescents was conducted at the Children's National Health System (Washington DC, USA) [Institutional Review Board Protocol No. 4718] and considered three overweight [body mass index (BMI) for age 85 th to $\leq 95$ th percentile] and 16 obese (BMI for age $\geq 95$ th percentile) adolescents between 12 and 18 years of age undergoing general surgery (such as orthopaedic surgery, tonsillectomy, bariatric surgery) [27]. The study in the morbidly obese adults (BMI $>40 \mathrm{~kg} / \mathrm{m}^{2}$ ) undergoing bariatric surgery was conducted at St. Antonius 
Hospital (Nieuwegein, The Netherlands) [VCMO NL35861.100.11, EudraCT 2011-003293-93] [14]. Before participation, patients of both studies provided written informed consent. Both studies were conducted in accordance with the principles of the Declaration of Helsinki. Patient characteristics of both studies are summarised in Table 1 .

\subsection{Study Procedure for Obese Adolescents}

Obese adolescents received a single intravenous bolus dose of 2 or $3 \mathrm{mg}$ a few minutes before they were taken to the operating room. Blood samples were collected at $T=0$, (5), 15 and $30 \mathrm{~min}$ and 1, 2, 4, 6 and occasionally at $8 \mathrm{~h}$. More information on the study procedure can be found in the published paper [27].

\subsection{Study Procedure for Morbidly Obese Adults}

Morbidly obese adults received $7.5 \mathrm{mg}$ of midazolam orally followed by a $5 \mathrm{mg}$ intravenous bolus dose of midazolam at induction of anaesthesia (159 \pm 67 min after the oral dose). Blood samples were collected at $T=0,5$, $15,30,45,55,65,75,90,120$ and $150 \mathrm{~min}$ after the oral dose and $T=5,15,30,90,120,150,180,210,270,330$, 390 and $510 \mathrm{~min}$ after the intravenous dose. More information on the study procedure can be found in the published paper [14].

\subsection{Population Pharmacokinetic Analysis and Internal Model Validation}

All data were analysed using non-linear mixed-effects modelling with NONMEM version 7.2 (ICON Development Solutions, Hanover, MD, USA) [28]. Pirana (2.9.1)
[29], R (3.0.1) [30], Xpose (4.5.0) [29] and Psn (3.6.2) [29] were used to evaluate and visualise the data. Of the 129 midazolam plasma samples of obese adolescents, no observations were below the limit of quantification $(0.5 \mathrm{ng} / \mathrm{mL})$ [27]. Of the total of 434 samples from the morbidly obese adults, 33 values $(7.6 \%)$ were below the limit of detection and removed from the analysis. Midazolam plasma concentrations between the limit of quantification $(<0.8 \mathrm{ng} / \mathrm{mL})$ and limit of detection $(<0.3 \mathrm{ng} /$ $\mathrm{mL})$ [14] were kept in the analysis $(n=9)$. The first-order conditional estimation method with interaction was used for model development. Discrimination between different models was guided by the likelihood ratio test comparing the objective function value (OFV, i.e. $-2 \log$ likelihood) between nested models. A $p$ value of $<0.05$, representing a decrease of 3.84 in OFV for one degree of freedom, was considered statistically significant. In addition, goodnessof-fit plots (observed vs. individual predicted concentrations, observed vs. population predicted concentrations, conditional weighted residuals vs. time after dose, and conditional weighted residuals vs. population predicted concentrations plots) upon midazolam in morbidly obese adults and obese adolescents were used for diagnostic purposes. Furthermore, precision of parameter estimates, the correlation matrix and visual improvement in the individual plots were used to evaluate the model. Pharmacokinetic models incorporating two or three compartments for midazolam were tested. The oral data of the morbidly obese adults were described by optimization of a five transit absorption compartment model, in which the transit compartment rate constant $\left(K_{\text {tr }}\right)$ was equalised to the oral absorption rate constant $\left(K_{\mathrm{a}}\right)$ [14]. Inter-individual variability was assumed to follow a log normal distribution. Residual variability was tested using proportional, additive, or combined proportional and
Table 1 Demographic parameters of 19 obese adolescents [27] and 20 morbidly obese adults [14]

\begin{tabular}{|c|c|c|}
\hline Parameter & Overweight and obese adolescents $(n=19)$ & Morbidly obese adults $(n=20)$ \\
\hline Female/male & $13 / 6$ & $12 / 8$ \\
\hline Overweight/obese & $3 / 16$ & \\
\hline Age (years) & $15.9 \pm 1.6(12.5-18.9)$ & $43.6 \pm 7.6(26-57)$ \\
\hline Body weight (kg) & $102.7 \pm 24.9(62-149.8)$ & $144.4 \pm 21.7(112.3-186.3)$ \\
\hline BMI $\left(\mathrm{kg} / \mathrm{m}^{2}\right)$ & $36.1 \pm 8.1(24.8-55)$ & $47.1 \pm 6.5(39.9-67.6)$ \\
\hline BMI $z$ score & $2.2 \pm 0.4(1.5-2.7)$ & \\
\hline LBW $(\mathrm{kg})[31]$ & $57.3 \pm 11.1(39.8-74.4)$ & $71.5 \pm 11.9(53.4-94.9)$ \\
\hline $\mathrm{WT}_{\text {for age and length }}(\mathrm{kg})$ & $57.8 \pm 7.6(43-72.3)$ & \\
\hline $\mathrm{WT}_{\text {excess }}(\mathrm{kg})$ & $44.8 \pm 21.9(14.6-92)$ & \\
\hline$\% \mathrm{WT}_{\text {excess }}(\%)$ & $77.4 \pm 37.1(30.8-159.1)$ & \\
\hline
\end{tabular}

Values are expressed as mean \pm standard deviation (range) unless specified otherwise $B M I$ body mass index, $L B W$ lean body weight, $W T_{\text {excess }}$ excess body weight, $W T_{\text {for age and length }}$ developmental weight 
additive error models. For internal model evaluation, a stratified bootstrap resampling method with 1000 replicates and normalised prediction distribution errors with 1000 simulations were used.

\subsection{Covariate Analysis}

Covariates were study population, TBW, BMI, lean body weight according to the equation of Janmahasatian et al. [31], age, race and sex. Covariates were plotted independently against the eta $(\eta)$ estimates of the pharmacokinetic parameters to visualise potential relations. Continuous covariates were tested using linear and power equations (Eqs. 1, 2):

$P_{\mathrm{i}}=P_{\mathrm{p}} \times\left(1+Y \times\left(\mathrm{COV}-\mathrm{COV}_{\text {median }}\right)\right)$,

$P_{\mathrm{i}}=P_{\mathrm{p}} \times\left(\mathrm{COV} / \mathrm{COV}_{\text {median }}\right)^{X}$

where $P_{\mathrm{i}}$ and $P_{\mathrm{p}}$ represent individual and population parameter estimates, respectively, $\mathrm{COV}$ represents the covariate, $\mathrm{COV}_{\text {median }}$ represents the median value of the covariate for the population, $Y$ represents the linear relationship between the population pharmacokinetic parameter and the change in covariate value for a linear function, and $X$ represents the exponent for a power function. The categorical covariates sex and study population were examined by estimating a separate parameter for each category of the covariate.

Potential covariates were entered into the model one at a time and statistically tested by the likelihood ratio test. In addition, if applicable, a reduction in inter-individual variability (omega) of the parameter was evaluated upon inclusion of the covariate on the parameter. Further, trends in the random effects of the parameter vs. the covariate involved were observed. After forward inclusion $(p<0.01)$, a backward exclusion procedure was applied to justify the inclusion of a covariate $(p<0.001)$. The choice of the covariate model was further evaluated as discussed in Sect. 2.4.

\subsection{Excess Weight Covariate Model}

To further analyse the influence of excess weight on the pharmacokinetics of midazolam for the obese adolescents, an excess weight covariate model was tested for the parameters for which TBW proved a covariate, as described under covariate analysis. In this model, the TBW of obese adolescents was considered to be composed of two parts: developmental weight $\left(\mathrm{WT}_{\text {for age and length }}\right)$ and excess body weight $\left(\mathrm{WT}_{\text {excess }}\right)$ [27]. For each individual adolescent of the study, $\mathrm{WT}_{\text {for age and length }}, \mathrm{WT}_{\text {excess }}$ and relative $\mathrm{WT}_{\text {excess }}\left(\% \mathrm{WT}_{\text {excess }}\right)$ were calculated using Eqs. 3, 4 and 5 respectively:

$$
\begin{aligned}
& \mathrm{WT}_{\text {for age and length }}=\mathrm{BMI}_{\text {without overweight }} \times \text { length }^{2}, \\
& \mathrm{WT}_{\text {excess }}=\mathrm{TBW}-\mathrm{WT}_{\text {for age and length }}, \\
& \% \mathrm{WT}_{\text {excess }}=\left(\mathrm{WT}_{\text {excess }} / \mathrm{WT}_{\text {for age and length }}\right) \times 100 \%,
\end{aligned}
$$

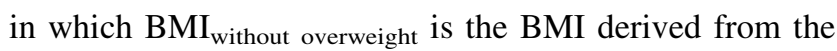
BMI-for-age Centers for Disease Control and Prevention growth chart (sex specific) at a BMI $z$ score of 0 together with the age of the patient [32] and TBW is the total body weight of the patient.

First, $\mathrm{WT}_{\text {for age and length, }} \mathrm{WT}_{\text {excess }}$ and $\% \mathrm{WT}_{\text {excess }}$ were plotted independently against the eta estimate for clearance to visualise the relation. Then, the impact of $\mathrm{WT}_{\text {for age }}$ and length and $\mathrm{WT}_{\text {excess }}$ on clearance in adolescents was evaluated using Eqs. 6 and 7:

$$
\begin{aligned}
& \mathrm{CL}_{\text {non-obese adolescent }}= \mathrm{CL}_{\text {non-obese adults }} \\
& \times\left(\mathrm{WT}_{\text {for age and length }} / 70\right)^{0.75} \\
& \mathrm{CL}_{\text {(obese) adolescent }}=\mathrm{CL}_{\text {non-obese adolescent }}+\left(Y \times \mathrm{WT}_{\text {excess }}\right),
\end{aligned}
$$

in which $\mathrm{CL}_{\text {non-obese adolescent }}$ represents the clearance estimate of adolescents without overweight with $\mathrm{CL}_{\text {non- }}$ obese adults representing the population clearance of nonobese adults [14], $\mathrm{WT}_{\text {for age and length }}$ representing developmental weight and 0.75 being the scaling factor that was previously proposed by the Food and Drug Administration for scaling clearance in (non-obese) adolescents [22]. $\mathrm{CL}_{\text {(obese) adolescent }}$ represents the individual clearance estimates of (obese) adolescents and $Y$ represents the linear relationship between clearance estimates of adolescents without overweight $\left(\mathrm{CL}_{\text {non-obese adolescent }}\right)$ and the change in clearance with $\mathrm{WT}_{\text {excess }}$.

\section{Results}

\subsection{Patients and Data}

The pharmacokinetic analysis was based on 530 observations from 19 obese adolescents [27] and 20 morbidly obese adults [14]. A summary of all patient characteristics is presented in Table 1 .

\subsection{Population Pharmacokinetic Model and Internal Model Evaluation}

Based on the data, a two-compartment model was identified, in which study population proved a significant covariate for clearance. Figure 1 shows that midazolam clearance in obese adolescents was significantly higher compared with morbidly obese adults $(\triangle \mathrm{OFV}-8.0$; $p<0.01)$. Moreover, in obese adolescents, midazolam 


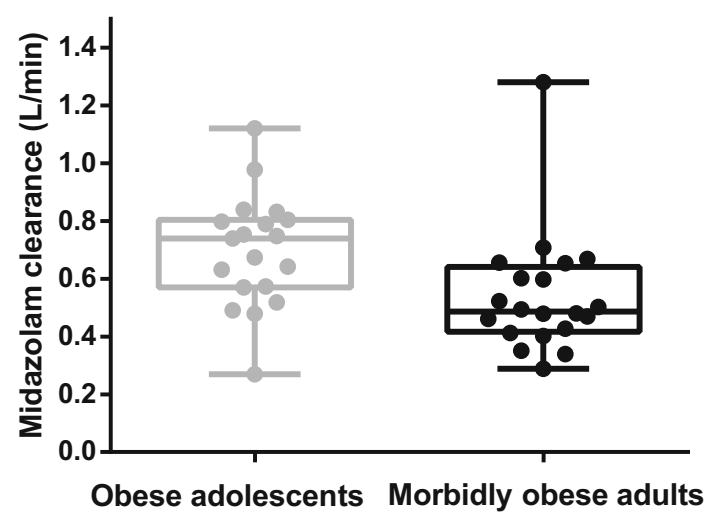

Fig. 1 Empirical Bayes estimates (EBEs) of midazolam clearance for obese adolescents (grey) and morbidly obese adults (black) of the base model

clearance increased significantly with TBW $(\Delta \mathrm{OFV}-10.6$; $p<0.01$ ). As a third covariate, the peripheral volume of distribution of morbidly obese adults increased significantly with TBW in a non-linear manner $(\triangle \mathrm{OFV}-10.9$; $p<0.001$ ). All three covariates fulfilled the criteria of the backward analysis $(p<0.001)$. No significant trend was found for TBW and clearance in the morbidly obese adults, nor for TBW and peripheral volume of distribution of midazolam in the obese adolescents $(p>0.05)$. No other covariates (age, BMI, lean body weight [31], race and sex) had a significant influence on any of the pharmacokinetic parameters $(p>0.05)$. The model parameters of the base model without covariates and the final covariate model are summarised in Table 2. Observed vs. individual predicted concentrations and observed vs. population predicted concentrations for midazolam in morbidly obese adults and obese adolescents are shown in Fig. 2. The final model was validated by 1000 bootstrap runs, which were successful in 93\% of the runs and confirmed the parameter values (Table 2). In addition, a normalised prediction distribution error analysis was performed showing no trends or bias for the two populations (Electronic Supplementary Material).

To further analyse the influence of excess weight in obese adolescents, in Fig. 3, clearance in obese adolescents is plotted against developmental weight $\left(\mathrm{WT}_{\text {for age and }}\right.$ length) and excess body weight ( $\mathrm{WT}_{\text {excess }}$ and $\left.\% \mathrm{WT}_{\text {excess }}\right)$. Figure 3 shows no obvious trend between $\mathrm{WT}_{\text {for age and }}$ length and midazolam clearance in obese adolescents, while a positive trend was observed between $\mathrm{WT}_{\text {excess }}$ or $\% \mathrm{WT}_{\text {excess }}$ and midazolam clearance $(\Delta \mathrm{OFV}-8.5$ and $-5.7 ; p<0.01$ and $p<0.05$, respectively). To capture the potential contribution of these different weight measures in obese adolescents, we propose an excess weight covariate model (Eqs. 6 and 7, Sect. 2), in which $\mathrm{WT}_{\text {for age and length }}$ was scaled on the basis of $70 \mathrm{~kg}$ to the power of 0.75 (Eq. 6) $[22,23]$, while for the influence of $\mathrm{WT}_{\text {excess }}$, a separate function was estimated (Eq. 7). Figure 4 shows the results of this excess weight model in which the final covariate model for clearance in obese adolescents (Table 2) was replaced by the excess weight covariate model. This figure illustrates that using this approach $\mathrm{WT}_{\text {for age and length }}$ scales allometrically to the power of 0.75 (Eq. 6), and that the influence of $\mathrm{WT}_{\text {excess }}$ was characterised using Eq. 7, estimating a $Y$ of 0.00698 (25\%), while the other parameter estimates were similar to the final covariate model (Table 2). The excess weight covariate model was as able as the final covariate model to describe the data in terms of OFV (2488.0 vs. 2487.0; $p>0.05$, Table 2) and goodness-of-fit plots.

\section{Discussion}

In this analysis, we report on the clearance of the CYP3A substrate midazolam in obese adolescents and morbidly obese adults. Throughout paediatric life, clearance is known to increase for which allometric scaling with an exponent of 0.75 is often used [19-21, 23]. Particularly for adolescents, there is hardly any debate on the use of this type of scaling [22]. In obesity, CYP3A activity seems to be suppressed, which was not only supported by in-vitro and obese mice studies [10-13], but also by the reported increased CYP3A-mediated midazolam clearance after substantial weight reduction upon bariatric surgery in morbidly obese patients [15-17]. An important question is how the CYP3A system is influenced by both age and obesity, particularly in view of the increasing prevalence of obesity in both adults and children.

This current study shows that obese adolescents have a higher midazolam clearance compared with morbidly obese adults. This finding is unexpected, because in general adolescents are anticipated to have a lower clearance compared with adults. However, the higher clearance in obese adolescents may perhaps not be so unexpected when recent studies on midazolam in morbidly obese patients before and after bariatric surgery are taken into consideration $[14,15]$. In one study, morbidly obese adults showed no change in clearance compared with non-obese adults [14]. These results are explained by postulating that a higher liver volume and/or liver blood flow will counteract the previously reported lower CYP3A protein expression or activity [10-13] caused by an increased inflammation state $[12,25,26,33]$, ultimately resulting in a similar absolute hepatic CYP3A-metabolizing capacity in both groups [14]. This hypothesis was supported by another study, in which the pharmacokinetic study was repeated 1 year after bariatric surgery in 18 of the 20 patients of the morbidly obese study group, when they had on average lost $44.5 \pm 10.2 \mathrm{~kg}$ of body weight [15]. Using the exact same study design, 
Table 2 Population pharmacokinetic parameters of the base and final pharmacokinetic model for midazolam in 19 obese adolescents and 20 morbidly obese adults and results of bootstrap analysis of the final model (927/1000 resamples successful)

\begin{tabular}{|c|c|c|c|c|}
\hline Parameter & $\begin{array}{l}\text { Base model } \\
\text { (RSE\%) }\end{array}$ & $\begin{array}{l}\text { Excess weight } \\
\text { model (RSE\%) }\end{array}$ & $\begin{array}{l}\text { Final model } \\
\text { (RSE\%) }\end{array}$ & $\begin{array}{l}\text { Bootstrap ( } 95 \% \\
\text { confidence interval) }\end{array}$ \\
\hline \multicolumn{5}{|l|}{ Fixed effects } \\
\hline $\mathrm{CL}(\mathrm{L} / \mathrm{min})$ & $0.58(7)$ & & & \\
\hline \multicolumn{5}{|c|}{$\mathrm{CL}_{\text {obese adolescents }}=\mathrm{CL}_{104.7 \mathrm{~kg}} \times(\mathrm{TBW} / 104.7)^{\mathrm{W}}$} \\
\hline $\mathrm{CL}_{104.7 \mathrm{~kg}}$ & & & $0.71(7)$ & $0.71(0.59-0.78)$ \\
\hline $\mathrm{W}$ & & & $1.2(31)$ & $1.19(1.08-1.99)$ \\
\hline $\mathrm{CL}_{\text {morbidly obese adults }}(\mathrm{L} / \mathrm{min})$ & & & $0.44(11)$ & $0.44(0.33-0.56)$ \\
\hline \multicolumn{5}{|c|}{$\mathrm{CL}_{\text {(obese) adolescent }}=\mathrm{CL}_{\text {non-obese adults }}$} \\
\hline \multicolumn{5}{|c|}{$\times\left(\mathrm{WT}_{\text {for age and length }} / 70\right)^{0.75}+\left(Y \times \mathrm{WT}_{\text {excess }}\right)$} \\
\hline $\mathrm{CL}_{\text {non-obese adults }}$ & & $0.45(20)$ & & \\
\hline$Y$ & & $0.007(25)$ & & \\
\hline$F$ & $0.589(12)$ & $0.56(14)$ & $0.562(12)$ & $0.563(0.45-0.74)$ \\
\hline$K_{\mathrm{a}}=K_{\mathrm{tr}}\left(\min ^{-1}\right)$ & $0.114(11)$ & $0.114(23)$ & $0.115(11)$ & $0.115(0.09-0.142)$ \\
\hline$V_{\text {central }}(\mathrm{L})$ & $55.4(11)$ & $53.7(12)$ & $55.2(11)$ & $54.7(42.2-66.8)$ \\
\hline$V_{\text {peripheral }}(\mathrm{L})$ & $161(12)$ & & & \\
\hline$V_{\text {peripheral obese adolescents }}(\mathrm{L})$ & & $168(15)$ & $172(13)$ & $172.8(132.9-235.1)$ \\
\hline \multicolumn{5}{|c|}{$V_{\text {peripheral morbidly obese adults }}=V_{141.8 \mathrm{~kg}}$} \\
\hline \multicolumn{5}{|l|}{$\times(\mathrm{TBW} / 141.8)^{\mathrm{X}}$} \\
\hline$V_{141.8 \mathrm{~kg}}$ & & $168(15)$ & $172(13)$ & $172.8(132.9-235.1)$ \\
\hline$X$ & & $3.2(58)$ & $3.3(33)$ & $3.19(1.08-5.33)$ \\
\hline $\mathrm{Q}(\mathrm{L} / \mathrm{min})$ & $1.14(12)$ & $1.15(11)$ & $1.14(12)$ & $1.14(0.91-1.47)$ \\
\hline \multicolumn{5}{|l|}{ Inter-individual variability (\%) } \\
\hline $\mathrm{CL}$ & $39.9(14)$ & $22.6(36)$ & $21(26)$ & $17.8(4.2-33.4)$ \\
\hline$F$ & $42.9(23)$ & $39.2(22)$ & $39.2(21)$ & $38.2(16.7-53.5)$ \\
\hline$K_{\mathrm{a}}=K_{\mathrm{tr}}$ & $49.2(17)$ & $50.4(12)$ & $49.5(17)$ & $48.2(34.9-61.0)$ \\
\hline$V_{\text {central }}$ & $62(11)$ & $54.4(22)$ & $58.5(11)$ & $56.2(28.1-83.0)$ \\
\hline$V_{\text {peripheral }}$ & $41.9(20)$ & $39.6(30)$ & $42.2(22)$ & $37.1(10.7-60.2)$ \\
\hline$Q$ & 40.9 (17) & $43.7(22)$ & $42.4(25)$ & $41.1(18.7-56.7)$ \\
\hline \multicolumn{5}{|l|}{ Residual variability (\%) } \\
\hline Proportional error & $29.6(9)$ & $29.9(9)$ & $29.7(9)$ & $29.6(24.6-35.0)$ \\
\hline OFV $(-2 L L)$ & 2516.6 & 2488 & 2487.0 & 2463.2 \\
\hline
\end{tabular}

$C L$ clearance of midazolam, $F$ oral bioavailability, $K_{a}$ absorption rate constant, $K_{t r}$ transit compartment rate constant, $O F V$ objective function value, $Q$ inter-compartmental clearance of midazolam between the central and peripheral compartment, $R S E$ relative standard error, $T B W$ total body weight, $V$ volume of distribution

the bariatric patients showed a 1.7 higher midazolam clearance compared with the situation before surgery [15] (Fig. 5). This increase was anticipated to result from the recovery of obesity-suppressed hepatic CYP3A activity as a consequence of the decreased inflammation status after weight loss from bariatric surgery [15]. A semi-physiologically based pharmacokinetic model including the 1-OH-midazolam metabolite confirmed this finding, where the intrinsic hepatic clearance of midazolam was 1.5 times higher in bariatric patients compared with morbidly obese patients before surgery [16]. As such, our finding of a higher total midazolam plasma clearance in obese adolescents compared with morbidly obese adults, can in our opinion be explained by the hypothesis that the CYP3A activity in obese adolescents is not (yet) suppressed to the same extent as morbidly obese adults. Perhaps the duration of (morbid) obesity and thereby the inflammatory status that goes with obesity, is of influence on the final CYP3A activity in the liver and can be considered the explanation for our findings. Even though from the data this hypothesis cannot be proven as no specific data on the duration of obesity are available, this explanation seems more likely than other differences between the groups such as differences in surgical procedure, anaesthetic regimen or BMI. 


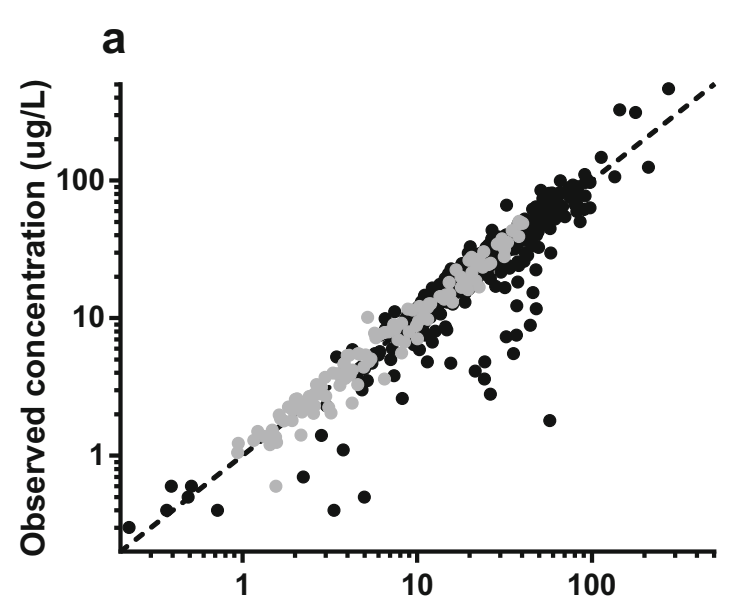

Individual predicted concentration (ug/L)

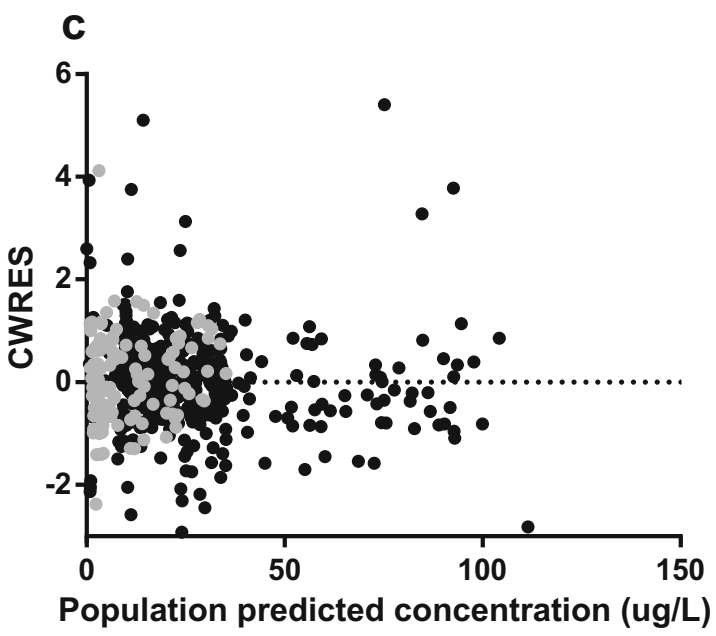

Fig. 2 a Observed vs. individual predicted concentrations, $\mathbf{b}$ observed vs. population predicted concentrations, c conditional weighted residuals (CWRES) vs. population predicted concentrations and

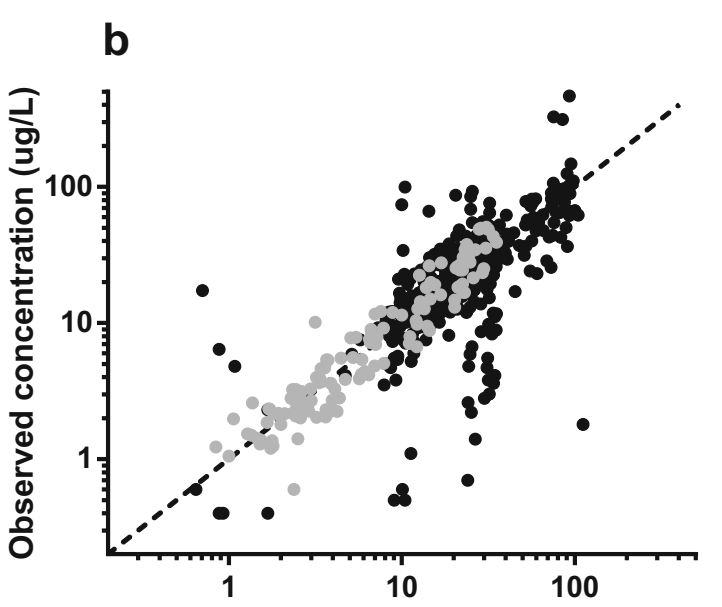

Population predicted concentration (ug/L)

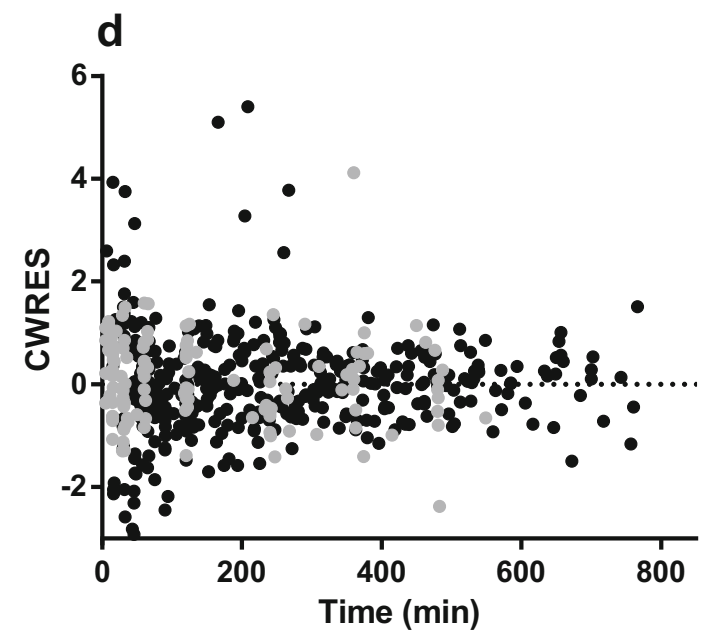

d CWRES vs. time of the final pharmacokinetic midazolam model for 19 obese adolescents (grey dots) and 20 morbidly obese adults (black dots)
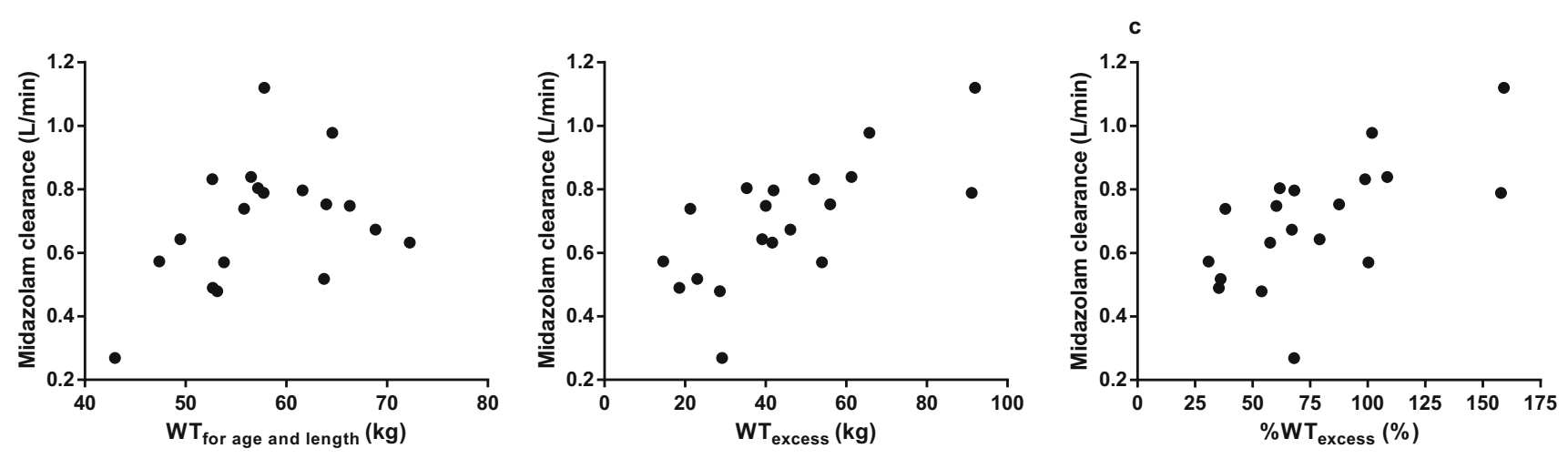

Fig. 3 Empirical Bayes estimates (EBEs) of midazolam clearance in adolescents vs. a body weight related to size (WT $\mathrm{W}_{\text {for age and length }}$ and b excess body weight $\left(\mathrm{WT}_{\text {excess }}\right)$ and c relative excess body weight $\left(\% \mathrm{WT}_{\text {excess }}\right)$ of the base model

This study also shows that the midazolam clearance in obese adolescents seems even higher than in healthy nonobese volunteers (Fig. 5) [14]. Based on this finding, it is hypothesised that obese adolescents have, besides the (yet) unaffected CYP3A activity, an increased liver size or increased liver blood flow and/or perfusion like morbidly obese adults [16, 34, 35]. This is further substantiated by the result that within the obese adolescent population, 


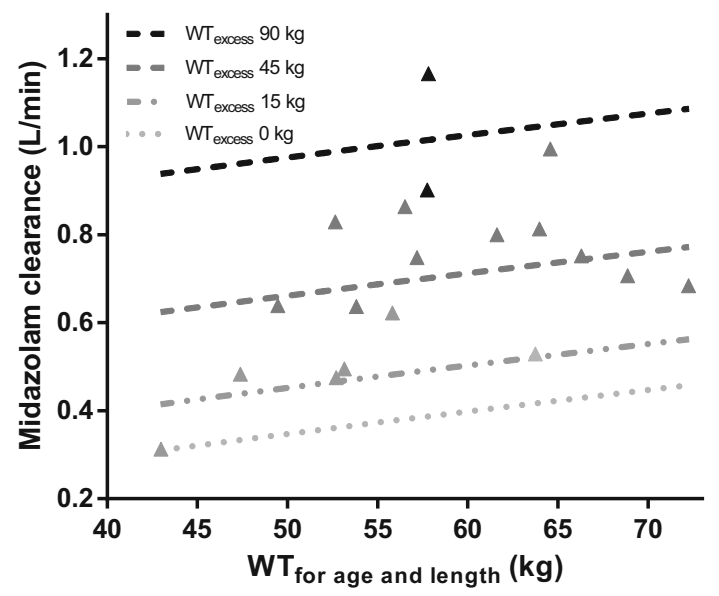

Fig. 4 Midazolam clearance [population predicted (line) and empirical Bayes estimates (triangles)] in obese adolescents vs. $\mathrm{WT}_{\text {for age }}$ and length. Population clearance values of adolescents without overweight $\left(\mathrm{WT}_{\text {excess } 0 \mathrm{~kg}}\right.$, dotted line) is calculated by scaling the clearance of adults on the basis of $70 \mathrm{~kg}$ to the power of 0.75 (Eq. 6) [22]. Population clearance values of the obese adolescents $\left(\mathrm{WT}_{\text {excess }}\right.$ of 15,45 and $90 \mathrm{~kg}$, dark grey/black lines) are composed of the clearance of adolescents without overweight $\left(\mathrm{WT}_{\text {excess } 0 \mathrm{~kg}}\right)$ supplemented by $\mathrm{WT}_{\text {excess }}$ of the obese adolescent times $Z$ (Eq. 7). Observed individual values of obese adolescents are represented by triangles with colors varying according to the degree in $\mathrm{WT}_{\text {excess }}$

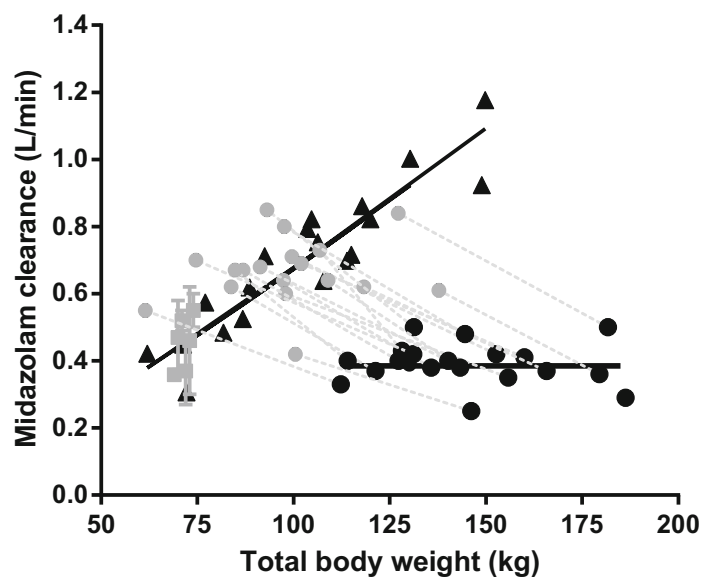

Fig. 5 Empirical Bayes estimates (EBEs) of midazolam clearance of 19 obese adolescents (black triangles) of the final pharmacokinetic model vs. body weight. Values reported for 20 morbidly obese patients (black dots) and 18 of the 20 morbidly obese patients 1 year after bariatric surgery [15] (grey dots, with dotted lines for corresponding values of these individuals at bariatric surgery) and healthy volunteer studies (grey squares) [14, 47-53] are added for comparison. Black lines are population mean estimates. Adapted from Brill et al. [15] with permission

midazolam clearance increases with TBW (Fig. 5), which was mainly explained by excess body weight ( $\left.\mathrm{WT}_{\text {excess }}\right)$ instead of developmental weight ( $\left.\mathrm{WT}_{\text {for age and length }}\right)$ (Figs. 3, 4). Concerning the increase in liver blood flow with body weight in obese adolescents, there is some evidence from a study on propofol, which is a high extraction ratio drug of which the clearance is mainly defined by liver blood flow [36]. In this study, propofol clearance was found to increase with body weight in (morbidly) obese adolescents, indicating an increase in liver blood flow in this population. This would point to a combination of an increase in liver blood flow and unaffected CYP3A activity being responsible for the elevated midazolam clearance in obese adolescents.

When analysing pharmacokinetic data in obese adolescents, it is important to be able to distinguish between the influence of body weight resulting from development or size and from obesity on the pharmacokinetic parameters [24]. Particularly because the prevalence of obesity in children is increasing, which complicates scaling on the basis of body weight. Previously, for busulfan, a model was proposed evaluating the pharmacokinetics in under-, normal and overweight children, adolescents and adults [median age of $4(0.1-35)$ years] [37]. The authors proposed to divide the body weight of each patient into body weight related to growth (body weight-for-age, $\mathrm{BW}_{\text {for age }}$ ) and body weight related to under/overweight (body weight $z$ score, $\mathrm{BW}_{z \text { score}}$ ) with separate functions for each of these weights. This exploratory model showed that both $\mathrm{BW}_{\text {for age }}$ and $\mathrm{BW}_{z}$ score influenced busulfan clearance, each in their own way [37]. For the analysis of midazolam data in overweight and obese adolescents [27], this model was adjusted into the (over)weight covariate model, in which body weight for age and length $\left(\mathrm{WT}_{\text {for age and length }}\right)$ was used instead of $\mathrm{BW}_{\text {for age }}$ because the influence of length is more relevant for adolescents. Another approach was reported by Diepstraten et al. who performed a population pharmacokinetic metaanalysis on propofol data from morbidly obese adults, adolescents, children and their non-obese controls (body weight $37-184 \mathrm{~kg}$, age 9-79 years) [38]. In that report, propofol clearance was found to increase with body weight, while age was implemented as a second covariate using a bilinear function [38]. As such, propofol clearance values were found to increase with body weight but were systematically lower in adolescents as compared with adults, which is in contrast with the current results on the CYP3A substrate midazolam for which higher values in obese adolescents were found. The excess weight covariate model we proposed here, may in our opinion provide guidance on how to analyse data in obese adolescents or children in future paediatric studies, as the influence of weight from developmental growth and obesity are separated and the influence of weight excess can theoretically be positive or negative (Eq. 7). Such a model is particularly of relevance because the prevalence of obesity is not only increasing in adults but also in children, thereby complicating the analysis of (often scarce) paediatric data even further. 
It has been stated before that when dosing information is not available in obese children, data can be extrapolated from obese adults [39-41] provided practitioners consider the effects of growth and development on the pharmacokinetics relevant to the child's age [40-42]. However, based on our results, we conclude that data of morbidly obese adults cannot be extrapolated to obese children as the duration of obesity is probably of influence on the (patho)physiological changes that are related to obesity. Using the excess weight covariate model we propose here, TBW is divided into $\mathrm{WT}_{\text {for age and }}$ length and $\mathrm{WT}_{\text {excess }}\left(\mathrm{TBW}=\mathrm{WT}_{\text {for age and length }}+\mathrm{WT}_{\text {excess }}\right)$. Clearance for non-obese adolescents is calculated on the basis of $70 \mathrm{~kg}$ to the power of 0.75 using clearance values in nonobese adults (Eq. 6). While this approach is generally accepted, particularly for adolescents [22], an advantage of this approach is that data from non-obese adolescents are not per se needed even though visual inspection may be useful as we showed in Fig. 3a. Then, the influence of $\mathrm{WT}_{\text {excess }}$ on clearance can be separately identified using visual inspection (Fig. 3b, c) after which implementation of this covariate in the model can be applied. Using this approach, both the influence of size resulting from development/growth (i.e. $\mathrm{WT}_{\text {for age and length }}$ ) and size resulting from obesity ( $\left.\mathrm{WT}_{\text {excess }}\right)$ can be separately studied and accounted for (Figs. 3, 4). It seems that this function needs to be considered when clearance is scaled to adolescents, as the percentage of obesity is still increasing, especially in this age group.

One limiting factor of this study is that the obese adolescents had a different ethnical background (5 Caucasians, 9 African Americans, 5 Hispanics) compared with the morbidly obese adults (19 Caucasian, 1 African American). Although race was not a significant covariate for clearance in obese adolescents $(\Delta \mathrm{OFV}-0.5 ; p>0.05)$, there was a trend of a slightly higher clearance for the African American adolescents compared with the Caucasian or Hispanic adolescents. In our opinion, this result is however more likely explained by the fact that these African American obese adolescents had a higher body weight. In addition, multiple studies show that midazolam clearance is lower in African Americans compared with Caucasians [43-45], which suggests that our results could be even more extreme if the adolescents with the highest body weight were Caucasian. These ethnic differences are associated with different frequencies of the $C Y P 3 A 4 * 1 B$ allele [44], but these differences do not contribute substantially to the inter-individual variability of CYP3A clearance [44, 46].

\section{Conclusion}

This study shows that midazolam clearance is higher in obese adolescents compared with morbidly obese adults. A possible explanation is that the CYP3A activity in obese adolescents is not (yet) suppressed to the same extent as in morbidly obese adults. As in obese adolescents $\mathrm{WT}_{\text {excess }}$ was found to substantially influence clearance and their clearance is also higher than that of non-obese adults, it seems that this finding may be the result of an increased liver size, liver blood flow and/or perfusion. From these results it seems that obesity is a significant issue to consider when scaling from adults to adolescents.

\section{Compliance with Ethical Standards}

Funding No sources of funding were received for the preparation of this article.

Conflict of interest A. van Rongen, M. J. E. Brill, J. D. Vaughns, P. A. J. Välitalo, E. P. A. van Dongen, B. van Ramshorst, J. S. Barrett, J. N. van den Anker and C. A. J. Knibbe have no conflicts of interest directly relevant to the content of this article.

Ethics approval All procedures performed in studies involving human participants were in accordance with the ethical standards of the institutional and/or national research committee and with the 1964 Helsinki Declaration and its later amendments or comparable ethical standards.

Informed consent Informed consent was obtained from all individual participants included in the study.

Open Access This article is distributed under the terms of the Creative Commons Attribution-NonCommercial 4.0 International License (http://creativecommons.org/licenses/by-nc/4.0/), which permits any noncommercial use, distribution, and reproduction in any medium, provided you give appropriate credit to the original author(s) and the source, provide a link to the Creative Commons license, and indicate if changes were made.

\section{References}

1. Zanger UM, Schwab M. Cytochrome P450 enzymes in drug metabolism: regulation of gene expression, enzyme activities, and impact of genetic variation. Pharmacol Ther. 2013;138(10):103-41.

2. Kotlyar M, Carson SW. Effects of obesity on the cytochrome P450 enzyme system. Int $\mathbf{J}$ Clin Pharmacol Ther. 1999;37(132):8-19.

3. Brill MJ, Diepstraten J, van Rongen A, van Kralingen S, van den Anker JN, Knibbe CA. Impact of obesity on drug metabolism and elimination in adults and children. Clin Pharmacokinet. 2012;51(71):277-304.

4. Vet NJ, Brussee JM, de Hoog M, Mooij MG, Verlaat CW, Jerchel IS, et al. Inflammation and organ failure severely affect midazolam clearance in critically ill children. Am J Respir Crit Care Med. 2016;194(1):58-66.

5. Carcillo JA, Doughty L, Kofos D, Frye RF, Kaplan SS, Sasser H, et al. Cytochrome P450 mediated-drug metabolism is reduced in children with sepsis-induced multiple organ failure. Intensive Care Med. 2003;29(6):980-4.

6. Ince I, Knibbe CA, Danhof M, de Wildt SN. Developmental changes in the expression and function of cytochrome P450 3A isoforms: evidence from in vitro and in vivo investigations. Clin Pharmacokinet. 2013;52(5):333-45. 
7. de Wildt SN, Kearns GL, Leeder JS, van den Anker JN. Cytochrome P450 3A: ontogeny and drug disposition. Clin Pharmacokinet. 1999;37(6):485-505.

8. Thummel KE, Shen DD, Podoll TD, Kunze KL, Trager WF, Hartwell PS, et al. Use of midazolam as a human cytochrome $\mathrm{P} 450$ 3A probe: I. In vitro-in vivo correlations in liver transplant patients. $J$ Pharmacol Exp Ther. 1994;271(1):549-56.

9. Fuhr U, Jetter A, Kirchheiner J. Appropriate phenotyping procedures for drug metabolizing enzymes and transporters in humans and their simultaneous use in the "cocktail" approach. Clin Pharmacol Ther. 2007;81(12):270-83.

10. Kolwankar D, Vuppalanchi R, Ethell B, Jones DR, Wrighton SA, Hall SD, et al. Association between nonalcoholic hepatic steatosis and hepatic cytochrome P-450 3A activity. Clin Gastroenterol Hepatol. 2007;5(3):388-93.

11. Yoshinari K, Takagi S, Yoshimasa T, Sugatani J, Miwa M. Hepatic CYP3A expression is attenuated in obese mice fed a high-fat diet. Pharm Res. 2006;23(6):1188-200.

12. Ghose R, Omoluabi O, Gandhi A, Shah P, Strohacker K, Carpenter $\mathrm{KC}$, et al. Role of high-fat diet in regulation of gene expression of drug metabolizing enzymes and transporters. Life Sci. 2011;89(1-2):57-64.

13. Woolsey SJ, Mansell SE, Kim RB, Tirona RG, Beaton MD. CYP3A activity and expression in nonalcoholic fatty liver disease. Drug Metab Dispos. 2015;43(10):1484-90.

14. Brill MJ, van Rongen A, Houwink AP, Burggraaf J, van Ramshorst B, Wiezer RJ, et al. Midazolam pharmacokinetics in morbidly obese patients following semi-simultaneous oral and intravenous administration: a comparison with healthy volunteers. Clin Pharmacokinet. 2014;53(12):931-41.

15. Brill MJ, van Rongen A, van Dongen EP, van Ramshorst B, Hazebroek EJ, Darwich AS, et al. The pharmacokinetics of the CYP3A substrate midazolam in morbidly obese patients before and one year after bariatric surgery. Pharm Res. 2015;32(12):3927-36.

16. Brill M, Valitalo P, Darwich AS, van Ramshorst B, van Dongen H, Rostami-Hodjegan A, et al. Semiphysiologically based pharmacokinetic model for midazolam and CYP3A mediated metabolite 1-OH-midazolam in morbidly obese and weight loss surgery patients. CPT Pharmacomet Syst Pharmacol. 2016;5(1):20-30.

17. Tandra S, Chalasani N, Jones DR, Mattar S, Hall SD, Vuppalanchi R. Pharmacokinetic and pharmacodynamic alterations in the Roux-en-Y gastric bypass recipients. Ann Surg. 2013;258(2):262-9.

18. Ng M, Fleming T, Robinson M, Thomson B, Graetz N, Margono $\mathrm{C}$, et al. Global, regional, and national prevalence of overweight and obesity in children and adults during 1980-2013: a systematic analysis for the Global Burden of Disease Study 2013. Lancet. 2014;384(9945):766-81.

19. Anderson BJ, McKee AD, Holford NH. Size, myths and the clinical pharmacokinetics of analgesia in paediatric patients. Clin Pharmacokinet. 1997;33(5):313-27.

20. Momper JD, Mulugeta Y, Green DJ, Karesh A, Krudys KM, Sachs HC, et al. Adolescent dosing and labeling since the Food and Drug Administration Amendments Act of 2007. JAMA Pediatr. 2013;167(10):926-32.

21. Mahmood I. Dosing in children: a critical review of the pharmacokinetic allometric scaling and modelling approaches in paediatric drug development and clinical settings. Clin Pharmacokinet. 2014;53(15):327-46.

22. US Food and Drug Administration Center for Drug Evaluation and Research. Advisory Committee for Pharmaceutical Science and Clinical Pharmacology (ACPS-CP) meeting: summary minutes and FDA transcript. 14 March 2012.
23. Calvier EA, Krekels EH, Valitalo PA, Rostami-Hodjegan A, Tibboel D, Danhof M, et al. Allometric scaling of clearance in paediatric patients: when does the magic of 0.75 fade? Clin Pharmacokinet. 2017;56(3):273-85.

24. Knibbe CA, Brill MJ, van Rongen A, Diepstraten J, van der Graaf $\mathrm{PH}$, Danhof M. Drug disposition in obesity: toward evidencebased dosing. Annu Rev Pharmacol Toxicol. 2015;55(1):149-67.

25. Shoelson SE, Herrero L, Naaz A. Obesity, inflammation, and insulin resistance. Gastroenterology. 2007;132(6):2169-80.

26. Fantuzzi G. Adipose tissue, adipokines, and inflammation. J Allergy Clin Immunol. 2005;115(16):911-9 (quiz 920).

27. van Rongen A, Vaughns JD, Moorthy GS, Barrett JS, Knibbe CA, van den Anker JN. Population pharmacokinetics of midazolam and its metabolites in overweight and obese adolescents. Br J Clin Pharmacol. 2015;80(5):1185-96.

28. Beal S, Sheiner LB, Boeckmann A, Bauer RJ. NONMEM user's guides. (1989-2009). Ellicott City: Icon Development Solutions; 2009.

29. Keizer RJ, Karlsson MO, Hooker A. Modeling and simulation workbench for NONMEM: tutorial on Pirana, PsN, and Xpose. CPT Pharmacomet Syst Pharmacol. 2013;2(43):e50.

30. R Development Core Team. R: a language and environment for statistical computing. Vienna: R Foundation for Statatistical Computing; 2008.

31. Janmahasatian S, Duffull SB, Ash S, Ward LC, Byrne NM, Green B. Quantification of lean bodyweight. Clin Pharmacokinet. 2005;44(31):1051-65.

32. Centers for Disease Control and Prevention. Clinical growth charts. Available from http://www.cdc.gov/growthcharts/ clinical_charts.htm. Accessed 14 Dec 2014.

33. Renton KW. Regulation of drug metabolism and disposition during inflammation and infection. Expert Opin Drug Metab Toxicol. 2005;1(17):629-40.

34. Alexander JK, Dennis EW, Smith WG, Amad KH, Duncan WC, Austin RC. Blood volume, cardiac output, and distribution of systemic blood flow in extreme obesity. Cardiovasc Res Cent Bull. 1962;1(48):39-44.

35. Lewis MC, Phillips ML, Slavotinek JP, Kow L, Thompson CH, Toouli J. Change in liver size and fat content after treatment with Optifast very low calorie diet. Obes Surg. 2006;16(6):697-701.

36. Diepstraten J, Chidambaran V, Sadhasivam S, Esslinger HR, Cox SL, Inge TH, et al. Propofol clearance in morbidly obese children and adolescents: influence of age and body size. Clin Pharmacokinet. 2012;51(27):543-51.

37. Bartelink IH, van Kesteren C, Boelens JJ, Egberts TC, Bierings MB, Cuvelier GD, et al. Predictive performance of a busulfan pharmacokinetic model in children and young adults. Ther Drug Monit. 2012;34(307):574-83.

38. Diepstraten J, Chidambaran V, Sadhasivam S, Blusse van OudAlblas HJ, Inge T, van Ramshorst B, et al. An integrated population pharmacokinetic meta-analysis of propofol in morbidly obese and nonobese adults, adolescents, and children. CPT Pharmacomet Syst Pharmacol. 2013;2(8):e73.

39. Mulla H, Johnson TN. Dosing dilemmas in obese children. Arch Dis Child Educ Pract Ed. 2010;95(6):112-7.

40. Kendrick JG, Carr RR, Ensom MH. Pharmacokinetics and drug dosing in obese children. J Pediatr Pharmacol Ther. 2010;15(7):94-109.

41. Kendrick JG, Carr RR, Ensom MH. Pediatric obesity: pharmacokinetics and implications for drug dosing. Clin Ther. 2015;37(9):1897-923.

42. Rowe S, Siegel D, Benjamin DK Jr. Best Pharmaceuticals for Children Act-Pediatric Trials Network Administrative Core Committee. Gaps in drug dosing for obese children: a systematic review of commonly prescribed emergency care medications. Clin Ther. 2015;37(9):1924-32. 
43. Xie R, Tan LH, Polasek EC, Hong C, Teillol-Foo M, Gordi T, et al. CYP3A and P-glycoprotein activity induction with St. John's Wort in healthy volunteers from 6 ethnic populations. J Clin Pharmacol. 2005;45(3):352-6.

44. Wandel C, Witte JS, Hall JM, Stein CM, Wood AJ, Wilkinson GR. CYP3A activity in African American and European American men: population differences and functional effect of the CYP3A4*1B5'-promoter region polymorphism. Clin Pharmacol Ther. 2000;68(1):82-91.

45. Sowunmi A, Rashid TJ, Akinyinka OO, Renwick AG. Ethnic differences in nifedipine kinetics: comparisons between Nigerians, Caucasians and South Asians. Br J Clin Pharmacol. 1995;40(5):489-93.

46. Xie HG, Kim RB, Wood AJ, Stein CM. Molecular basis of ethnic differences in drug disposition and response. Annu Rev Pharmacol Toxicol. 2001;41:815-50.

47. Greenblatt DJ, Abernethy DR, Locniskar A, Harmatz JS, Limjuco RA, Shader RI. Effect of age, gender, and obesity on midazolam kinetics. Anesthesiology. 1984;61(13):27-35.

48. Thummel KE, O'Shea D, Paine MF, Shen DD, Kunze KL, Perkins JD, et al. Oral first-pass elimination of midazolam involves both gastrointestinal and hepatic CYP3A-mediated metabolism. Clin Pharmacol Ther. 1996;59(10):491-502.
49. Lee JI, Chaves-Gnecco D, Amico JA, Kroboth PD, Wilson JW, Frye RF. Application of semisimultaneous midazolam administration for hepatic and intestinal cytochrome P450 3A phenotyping. Clin Pharmacol Ther. 2002;72(8):718-28.

50. Mandema JW, Tuk B, van Steveninck AL, Breimer DD, Cohen AF, Danhof M. Pharmacokinetic-pharmacodynamic modeling of the central nervous system effects of midazolam and its main metabolite alpha-hydroxymidazolam in healthy volunteers. Clin Pharmacol Ther. 1992;51(24):715-28.

51. Gorski JC, Hall SD, Jones DR, VandenBranden M, Wrighton SA. Regioselective biotransformation of midazolam by members of the human cytochrome P450 3A (CYP3A) subfamily. Biochem Pharmacol. 1994;47(9):1643-53.

52. Shord SS, Chan LN, Camp JR, Vasquez EM, Jeong HY, Molokie $\mathrm{RE}$, et al. Effects of oral clotrimazole troches on the pharmacokinetics of oral and intravenous midazolam. Br J Clin Pharmacol. 2010;69(2):160-6.

53. van Gerven JM, Roncari G, Schoemaker RC, Massarella J, Keesmaat P, Kooyman H, et al. Integrated pharmacokinetics and pharmacodynamics of Ro 48-8684, a new benzodiazepine, in comparison with midazolam during first administration to healthy male subjects. Br J Clin Pharmacol. 1997;44(5):487-93. 